\begin{tabular}{|c|l|}
\hline Title & $\begin{array}{l}\text { Gene expression and genetic mapping analy ses of a perennial ry egrass glycine rich RNA-binding protein gene suggest a } \\
\text { role in cold adaptation }\end{array}$ \\
\hline Author(s) & Shinozuka, H.; Hisano, H.; Y oney ama, S.; Shimamoto, Y.; Jones, ES; Forster, JW; Y amada, T.; Kanazawa, A kira \\
\hline Citation & $\begin{array}{l}\text { MOLECULAR GENETICS AND GENOMICS, 275(4), 399-408 } \\
\text { https://doi.org/L0.1007/300438-005-0095-3 }\end{array}$ \\
\hline Issue Date & 2006-04 \\
\hline Doc URL & http://hdl.handle.net/2115/10083 \\
\hline Rights & The original publication is available at www.springerlink.com \\
\hline Type & article (author version) \\
\hline File Information & Shinozukatet+al+LLGRP1+MGG+for+HUSCAP.pdf \\
\hline
\end{tabular}

Instructions for use 


\section{Gene expression and genetic mapping analyses of a perennial ryegrass glycine-rich RNA-binding protein gene suggest a role in cold adaptation}

\section{H. Shinozuka, H. Hisano, S. Yoneyama, Y. Shimamoto, E. S. Jones, J. W. Forster,}

T. Yamada, A. Kanazawa

H. Shinozuka, H. Hisano, S. Yoneyama, Y. Shimamoto, A. Kanazawa (corresponding author)

Graduate School of Agriculture, Hokkaido University, Sapporo 060-8589, Japan

E-mail: kanazawa@res.agr.hokudai.ac.jp

Tel: +81-11-706-3873

Fax: +81-11-706-4933

E. S. Jones, J. W. Forster

Primary Industries Research Victoria, Victorian AgriBiosciences Centre, La Trobe University, Bundoora, Victoria 3083, Australia; and Molecular Plant Breeding Cooperative Research Centre, Australia

T. Yamada

Field Science Center for Northern Biosphere, Hokkaido University, Sapporo 060-0811, Japan

Present address:

Y. Shimamoto

Faculty of Bioindustry, Tokyo University of Agriculture, Abashiri, 099-2493, Japan

E. S. Jones

Present address: Crop Genetics Research and Development, Pioneer Hi-Bred International, $7300 \mathrm{NW} \mathrm{62}{ }^{\text {nd }}$ Avenue, Johnston, Iowa 50131-1004, United States of America 
Abstract A perennial ryegrass cDNA clone encoding a putative glycine-rich RNA binding protein (LpGRP1) was isolated from a cDNA library constructed from crown tissues of cold-treated plants. The deduced polypeptide sequence consists of 107 amino acids with a single N-terminal RNA recognition motif (RRM) and a single C-terminal glycine-rich domain. The sequence showed extensive homology to glycine-rich RNA binding proteins previously identified in other plant species. LpGRP1-specific genomic DNA sequence was isolated by inverse PCR amplification. A single intron which shows conserved locations in plant genes was detected between the sequence motifs encoding RNP-1 and RNP-2 consensus protein domains. Significant increase in the mRNA level of LPGRP1 was detected in root, crown and leaf tissues during the treatment of plants at $4^{\circ} \mathrm{C}$, through which freezing tolerance is attained. The increase in the mRNA level was prominent at least $2 \mathrm{hr}$ after commencement of the cold treatment, and persisted for at least one week. Changes in mRNA level induced by cold treatment were more obvious than those due to treatments with abscisic acid (ABA) and drought. The LpGRP1 protein was found to localize in the nucleus in onion epidermal cells, suggesting that it may be involved in pre-mRNA processing. The LpGRP1 gene locus was mapped to linkage group 2. Possible roles for the LpGRP1 protein in adaptation to cold environments are discussed.

Keywords: freezing tolerance; glycine-rich RNA-binding protein; Lolium perenne; post-transcriptional control; stress response 


\section{Introduction}

Post-transcriptional mechanisms for regulation of gene expression involve control of pre-mRNA processing, transportation to cytoplasm and mRNA stability. These regulatory mechanisms are mediated by specific interaction between RNA-binding proteins and RNA molecules. An increasing number of proteins containing conserved RNA-binding motifs have been identified (for a review, see Alba and Pages 1998). These motifs include the RNA-recognition motif (RRM), the arginine-rich motif, the RGG box, the hnRNP K homology motif, the Zn-finger motif and the double-stranded RNA binding motif. The best-characterized motif, RRM, contains two short sub-motifs designated RNP-1 and RNP-2. There is a family of proteins that contain a glycine-rich sequence (for a review, see Sachetto-Martins et al. 2000). Proteins that contain both an RRM and a glycine-rich region at the C-terminus (glycine-rich RNA-binding proteins) belong to protein families characteristic of each structural class. This class of proteins was identified first in plants (Gomez et al., 1988), and more recently, in mammals (Derry et al. 1995; Nishiyama et al. 1997) and cyanobacteria (Sato 1994; Sugita and Sugiura 1994). Maruyama et al. (1999) showed that the cyanobacterial RNA-binding proteins and eukaryotic glycine-rich proteins are similar to each other in both structure and regulation, and that this similarity has resulted from convergent evolution.

The glycine-rich RNA-binding proteins are widely distributed in plants, including both angiosperms and gymnosperms (Sachetto-Martins et al. 2000). An increase in gene expression in response to environmental stresses such as cold, drought or wounding is one of the typical features of plant glycine-rich RNA-binding proteins (Alba and Pages 1998; Sachetto-Martins et al. 2000). Ribohomopolymer-binding assays showed that glycine-rich RNA-binding proteins such as those from maize (MA16, Ludevid et al. 1992), Nicotiana sylvestris (GRP-1b, Hirose et al. 1993; RGP-3, Moriguchi et al. 1997), and barley (BLT801, Dunn et al. 1996) have high affinity for poly(G) and poly(U). 
Analyses of sub-cellular localization demonstrated that glycine-rich RNA-binding proteins from maize (MA16, Alba et al. 1994), N. sylvestris (RZ-1, Hanano et al. 1996; RGP-1b and RGP-3, Moriguchi et al. 1997), and Sinapis alba (SaGRP-1a, Heintzen et al. 1994) are located in nuclei. Recently, the MA16 protein was found to interact with RNA helicase (Gendra et al. 2004). Both the MA16 and RGP-1b proteins accumulate predominantly in the nucleolus, while the RGP-3 protein accumulates in nucleoplasm (Alba et al. 1994; Moriguchi et al. 1997). Because of these features, participation of the MA16 and RGP-1b proteins in pre-ribosomal RNA processing and/or rRNA transport to the cytoplasm, as well as participation of the RGP-3 protein in pre-mRNA processing, have been suggested (Alba et al. 1994; Moriguchi et al. 1997). It is also known that the expression of a glycine-rich RNA-binding protein in Arabidopsis thaliana (AtGRP1) is regulated according to a circadian clock through alternative pre-mRNA splicing (Staiger et al. 2003). The overall function of glycine-rich RNA-binding proteins is still unknown. However, these observations suggest that they are involved in the control of RNA processing and/or mRNA stability in response to environmental stimuli.

Like many other plants growing in global temperate regions, the agronomically important pasture grass species perennial ryegrass (Lolium perenne L.) can acquire freezing tolerance through exposure to low, non-lethal temperatures, a phenomenon known as cold acclimation. In addition to numerous physiological and biochemical changes, changes in gene expression at low temperatures have been detected for a large number of genes in plants, although limited information is available on the relationship between changes in gene expression and tolerance to low temperature (for a review, see Pearce 1999). To understand the mechanisms of freezing tolerance in perennial ryegrass, we have analyzed the process of adaptation to freezing in terms of changes in gene expression (Tominaga et al. 2001), alteration of cellular structural properties (Tominaga et al. 2004), and detection of quantitative trait loci (QTLs) for electrical conductivity of cell extracts that correlate with frost tolerance (Yamada et al. 2004). In the present study, 
we describe the isolation of the gene for a glycine-rich RNA-binding protein, and describe changes in gene expression during cold acclimation in perennial ryegrass. The cDNA and genomic DNA structure of the gene, subcellular localization of the protein, and location on the reference genetic map were also established.

\section{Materials and methods}

Plant materials

Plants from Lolium perenne cv. Aberystwyth S23 were used for gene isolation and analysis of gene expression. In order to assign the $L p G R P 1$ gene to the reference genetic map, 164 individuals from the p150/112 mapping population, derived from the cross between a multiple heterozygous parent of complex descent as pollinator and a doubled haploid as female parent (Jones et al. 2002a, 2002b), were analyzed.

Construction and screening of cDNA library

For construction of a cDNA library, total RNA was isolated from cold-treated perennial ryegrass plants. After germination of seeds in soil, plants were grown under conditions of $16 \mathrm{hr}$ light at $22^{\circ} \mathrm{C}$ and $8 \mathrm{hr}$ dark at $18^{\circ} \mathrm{C}$ each day in a plant growth room over a period of 30 days. These plants were used for cold treatment. For cold treatment, plants were kept under light for $8 \mathrm{hr}$ at $6^{\circ} \mathrm{C}$ and then in the dark for $16 \mathrm{hr}$ at $2^{\circ} \mathrm{C}$ each day in a cold acclimation room. Plants were maintained in this condition for 14 days. Total RNA was isolated from crown tissues of 30 individual plants using TRIzol reagent (GIBCO BRL). Poly(A) ${ }^{+}$RNA was purified using Dynabeads Oligo (dT)25 (Dynal). The cDNA was synthesized from the poly $(\mathrm{A})^{+} \mathrm{RNA}$ and then ligated to lambda phage vector using the lambda ZAP Express cDNA Synthesis Kit (Stratagene) according to the 
manufacturer's instructions. In vitro packaging was carried out using Gigapack Gold III Packaging Extract (Stratagene). A partial glycine-rich RNA-binding protein cDNA sequence was amplified by PCR from the perennial ryegrass cDNA using a combination of the oligo(dT) primer and a gene-specific primer (5'-TGCTTCGTGGGCGGCCTC-3'). The latter was designed based on a glycine-rich RNA-binding protein cDNA isolated from wheat (Guiltinan and Niu 1996; Imai, unpublished data). The amplified fragment was cloned into the pGEM-T Easy vector (Clontech) and was used as a probe to screen the cDNA library (total titre $=6 \times 10^{6} \mathrm{pfu}$ ) by plaque hybridisation using the ECL Direct gene detection system (Amersham Pharmacia Biotech) in order to obtain a full-length cDNA clone.

Inverse PCR

Genomic DNA from an individual plant of cultivar Aberystwyth S23 was digested with EcoRV or SacI, and circularized by self-ligation using the Ligation high system (TOYOBO). Two rounds of PCR were carried out for amplification. The first round of the PCR was carried out in a total volume of $50 \mu \mathrm{l}$ using self-ligated DNAs as a template with KOD-plus DNA polymerase (TOYOBO). The second round of the PCR was carried out using a $0.1 \mu 1$ aliquot of the reaction mixture from the first round of PCR. To amplify target sequences, primers Inv.PCR-lpgrp1-F1 (5'-GTTTAGCGGCAAGAATGGCG-3') and Inv.PCR-lpgrp1-R1 (5'-CCTACTAGACGAACCGGAAC-3') were used for the first round PCR, and primers Inv.PCR-lpgrp1-F2 (5'-AGAGTACCGTTGCTTCGTCG-3') and Inv.PCR-lpgrp1-R2 (5'-AACCGGGAACGAGGACTAGT-3') were used for the second round of PCR. The PCR cycling conditions were: $96^{\circ} \mathrm{C}$ for $30 \mathrm{sec}, 53^{\circ} \mathrm{C}$ for $30 \mathrm{sec}$, $72^{\circ} \mathrm{C}$ for $3 \mathrm{~min}$ for the first round PCR; and $96^{\circ} \mathrm{C}$ for $30 \mathrm{sec}, 56^{\circ} \mathrm{C}$ for $30 \mathrm{sec}$, and $72^{\circ} \mathrm{C}$ for $3 \mathrm{~min}$ for the second round PCR. These cycles were repeated 28 times, and the 
reaction mixture was then further incubated at $72^{\circ} \mathrm{C}$ for $5 \mathrm{~min}$. The PCR products were cloned into the pGEM-T Easy vector (Clontech) and were subjected to sequence analysis.

DNA sequence analysis

DNA sequencing was performed with a DNA sequencing kit and a DNA sequencer (ABI373; PERKIN ELMER Applied Biosystems) according to the manufacturer's instruction. Alignment of DNA sequence was carried out using CLUSTAL W Multiple Sequence Alignment Program version 1.8 (http://clustalw.genome.jp) (Thompson et al. 1994). The aligned sequences were displayed using BIOEDIT (Hall 1999). Regulatory DNA elements present in the 5' upstream sequence of the gene were identified using Plant Cis-Acting Regulatory DNA Elements (PLACE) database (http://www.dna.affrc.go.jp/PLACE/) (Higo et al. 1999).

Treatment of plants

Plants were grown in hydroponic culture in 1/4 MS medium (Murashige and Skoog 1962), pH 5.5 under $24 \mathrm{hr}$ lighting conditions at $22^{\circ} \mathrm{C}$ for 4 weeks. The culture medium was renewed every 10 days. The apparatus of hydroponic culture consisted of two parts. The upper part was a draining tray on which seeds were laid such that the roots elongated from the seeds could absorb water as well as nutrients from the liquid medium in the bottom tray. Cold treatment was carried out by transferring a draining tray (upper tray) on which plants were grown onto another bottom tray that had been kept at $4{ }^{\circ} \mathrm{C}$ in a cold room. RNA was isolated from plants before and ( $2 \mathrm{hr}$ and $6 \mathrm{hr}$ ) after transfer to the cold room. Abscisic acid (ABA) treatment was carried out by the same method: the upper tray was transferred onto another bottom tray in which $1 / 4 \mathrm{MS}$ 
medium was supplemented with $100 \mu \mathrm{M}$ ABA. RNA was isolated from plants $4 \mathrm{hr}$ after the ABA treatment. Drought stress was applied to plants by lifting up the upper tray and placing it onto paper towels to eliminate water. RNA was isolated from plants kept in a growth chamber for $2 \mathrm{hr}$ after this drought treatment. For cold treatments longer than 24 hr, soil-grown plants in a growth room were transferred to a cold acclimation room as described previously. RNA was isolated from plants cold-treated for 1, 3, 7, and 14 days after commencement of this treatment. The deacclimation treatment was performed by transferring the plants that had been cold-treated for 14 days to the plant growth room $\left(22^{\circ} \mathrm{C}\right)$. RNA was extracted from plants 14 days after they were transferred to the plant growth room.

Isolation of nucleic acids and gel blot analysis

Total DNA was isolated from an individual plant as described by Doyle and Doyle (1987). DNA $(30 \mu \mathrm{g})$ was digested with restriction enzymes and fractionated by electrophoresis on a $0.8 \%(\mathrm{w} / \mathrm{v})$ agarose gel. Total RNA was isolated from plants as described by Napoli et al. (1990). Total RNA (10 $\mu \mathrm{g})$ was fractionated by electrophoresis on a $1 \%$ agarose gel. After electrophoresis, nucleic acids were transferred to nylon membranes (Hybond N+, Amersham Pharmacia Biotech) and allowed to hybridise with labelled probes. Labelling of probes, hybridisation, washing of membranes, and detection of signals were carried out using the Alkphos Direct nucleic acid labelling and detection system (Amersham Pharmacia Biotech). The full-length $L p G R P 1$ cDNA sequence was labelled for use as a hybridisation probe.

Subcellular localization of LpGRP1 with enhanced green fluorescent protein (EGFP) fusion 
A DNA fragment containing the entire LPGRP1 coding region was amplified from a cDNA clone using primers "lpgrp1-For-BamHI" (5'-GGATCCATGGCGGAAGAGTACCGTTG-3') and "lpgrp1-Rev-G-NcoI" (5'-CCATGGCACCTCCACCTCCACCTCCGTTCCTCCAGTTGCCGGCAG-3'). The first six nucleotides of these primers provide restriction endonuclease sites that were used in subsequent plasmid construction. After cloning the PCR products into the pGEM-T Easy vector (Clontech), the BamHI-NcoI fragment of the plasmid containing the LpGRP1 gene was force-cloned across the BamHI and NcoI sites of a plasmid vector that contains the EGFP gene (Clontech) in place of the GUS gene of plasmid pBI221 (Clontech) in the downstream of the cauliflower mosaic virus 35S promoter (Fujino, unpublished). This permitted the synthesis of an LpGRP1-EGFP fusion protein with a stretch of 7 amino acids between the fusion partners. The LpGRP1-EGFP plasmid was introduced into the epidermal cells of onion (Allium cepa) by the particle bombardment method essentially as described previously (Hisano et al. 2004). Tissues were examined after overnight incubation on $1 / 2 \mathrm{MS}$ medium at $27^{\circ} \mathrm{C}$ in the dark using a fluorescence microscope (Olympus BX-51).

Genetic mapping of $L p G R P 1$ locus

Southern hybridisation analysis of DNA isolated from each individual of the mapping population was performed as described above. The scored genotypes were compared with segregation data of molecular markers (predominantly heterologous restriction fragment length polymorphisms [RFLPs] and amplified fragment length polymorphisms [AFLPs]) as described by Jones et al. (2002a) using MAPMAKER 3.0 (Lander et al. 1987) with a threshold confidence value of $\operatorname{LOD}>2.0$. Genetic map distances were estimated from recombination values by application of the Kosambi function (Kosambi 1944). Comparative genomics analysis was performed using the TBLASTX function in 
GrainGenes (http://wheat.pw.usda.gov./cgi-bin/blast) restricted to wheat expressed sequence tags (ESTs) assigned to mapped deletion bins (Qi et al. 2003). The locations of highest matching sequences were determined using the wEST SQL query function in GrainGenes (http://wheat.pw.usda.gov/wEST/).

Nucleotide sequence accession number

The LpGRP1 genomic DNA sequence has been submitted to DDBJ with the accession number AB207971.

\section{Results}

Cloning of LpGRP1 cDNA

Five clones were isolated from the perennial ryegrass cDNA library by hybridisation screening with a truncated putative glycine-rich RNA-binding protein cDNA. Partial sequencing analysis of these 5 clones revealed almost identical sequences. The longest putative full-length cDNA was 609 nucleotides long, discounting the poly(A)-tail, and encodes an open reading frame (ORF) from nucleotides 81 to 404 . The deduced polypeptide sequence consists of 107 amino acids with a predicted molecular weight of $11.3 \mathrm{kDa}$. The alignment of the amino acid sequence with those of cognate proteins from other plants indicated that the $\mathrm{N}$-terminal region containing an RRM domain is highly conserved (Fig. 1). The RRM contained perfect RNP-1 and RNP-2 sub-domain consensus sequences. The C-terminal region of the protein contained a glycine-rich sequence consisting of 22 amino acids. Because of these apparent structural characteristics, we designated the gene LpGRP1 (Lolium perenne glycine-rich RNA-binding protein 1). 
Isolation and analysis of the $L p G R P 1$ genomic DNA region

Genomic DNA for the LpGRP1 gene was isolated using the method of inverse PCR (I-PCR). Sequence analysis of the amplified DNA fragment revealed the presence of single intron within the coding sequence of the gene (Fig. 2), between the sequences that encode RNP-2 and RNP-1 within the RRM domain.

The 5' upstream sequence was examined for the presence of transcriptional regulatory sequences. Data base searches revealed various elements known to be responsible for transcriptional activation by cold and/or other environmental stresses, such as: a low-temperature-responsive element (LTRE; Dunn et al. 1998), an ABA-responsive element (ABRE; Marcotte et al. 1989), and a dehydration-responsive element/C-repeat (DRE/CRT; Dubouzet et al. 2003) as well as a circadian clock element (Harmer et al. 2000) (see Fig. 2). Although the actual roles of these regulatory elements in LPGRP1 transcription are yet to be determined, the presence of such elements suggests that the LpGRP1 expression may be inducible by low temperature.

Southern hybridisation analysis of perennial ryegrass genomic DNA with a LPGRP1 cDNA probe was performed and hybridisation signals of approximately $1.6 \mathrm{~kb}$ and $2.6 \mathrm{~kb}$ were detected for EcoRV- and SacI-digested DNA, respectively (data not shown). The sizes of these fragments corresponded with those anticipated from sequence analysis of amplified DNA, suggesting that the genomic sequence was not derived from artefactual amplification events, such as PCR-mediated recombination (Cronn et al. 2002).

Expression of $L p G R P 1$ gene in response to environmental stresses

Changes in the mRNA level of the gene during the process of cold treatment at $4^{\circ} \mathrm{C}$ 
were analyzed. Previous crown freezing tests using crown tissue have shown that cold treatment confers a significant freezing tolerance to various perennial ryegrass accessions. For instance, the survival rate of cultivar Riikka under freezing conditions at $-6^{\circ} \mathrm{C}$ for $16 \mathrm{hr}$ increased from $0 \%$ to $62 \%$ by virtue of the cold treatment (Yamashita et al. 1993). Northern blot analysis clearly indicated that the mRNA level of LpGRP1 increased during the cold treatment (Fig. 3A). The increase in the mRNA level was detectable for at least as early as $2 \mathrm{hr}$ after commencement of the cold treatment (Fig. 3B), and the increase continued over the next 1 week of cold treatment (Fig. 3A). The increased level of LPGRP1 mRNA remained unchanged during further cold treatment and reverted to pre-induction levels following transfer of plants to more normal conditions, leading to deacclimation of freezing tolerance (Fig. 3A). Expression of the LPGRP1 gene was consequently demonstrated to be clearly associated with cold stress. The increase in the mRNA level by the cold treatment was detected in leaf, root and crown tissues (Fig. 3C). The mRNA level was also increased in response to ABA and drought treatments (Fig. 3B). No changes in the plant appearance were observed following cold or ABA treatments, but drought treatment was associated with crinkled leaves and roots (data not shown).

Subcellular localization of the LpGRP1 protein

In order to determine the subcellular localization of the LpGRP1 protein, a transient expression assay was performed using a LpGRP1-EGFP reporter fusion protein. The LPGRP1-EGFP gene construct was introduced into epidermal cells of onion by particle bombardment, and fluorescence was observed under microscope. When the EGFP gene alone was introduced into cells as a control, EGFP-derived fluorescence was observed in both the cytoplasm and the nucleus (Fig. 4E) as reported previously (see, for examples, Genda et al. 2004; Sano and Tanaka 2005; Wang et al. 2005). In contrast, 
when EGFP was fused to the LpGRP1 protein, fluorescence of EGFP was detected only in the nucleus (Figs. 4A, 4B, 4C and 4D). In about $30 \%$ of observed nuclei, the fluorescence was missing from nucleoli and was detected only in nucleoplasm. It seems likely that LpGRP1 protein is capable of localization in both nucleoplasm and nucleoli.

Genetic map location of the LpGRP1 gene

The LPGRP1 gene was assigned to the reference genetic linkage map of perennial ryegrass through RFLP detected by Southern-hybridisation analysis of DraI-digested genomic DNA from the p150/112 population (Jones et al. 2002a, 2002b). In the $F_{1}$ progeny set of this one-way pseudo-testcross population, 3.3-kb and 3.6-kb DNA fragments detected by the LPGRP1 cDNA probe displayed exclusive allelic Mendelian segregation compatible with an $\mathrm{AB} \times \mathrm{BB}$ genetic structure (data not shown). The corresponding RFLP locus (designated as xlpgrp1) was located within the interval between the AFLP e40t49173 and the rice cDNA-detected heterologous RFLP marker xc472 in the distal part of linkage group (LG) 2 (data not shown), in a region of conserved synteny with the long arms of the wheat homoeologous group 2 chromosomes and rice chromosome 4 (Jones et al., 2002a). The estimated map distance between the xlpgrp1 and xc472 loci was $4.1 \mathrm{cM}$. It is possible that the LpGRP1 gene may be located close to genes for antifreeze proteins (AFPs; Sidebottom et al. 2000) on LG2, as AFP gene loci have been identified on the corresponding chromosome in meadow fescue (Festuca pratensis Huds.), (Humphreys et al. 2004), which is closely related to the Lolium species and shows a high level of conserved synteny and colinearity (Alm et al. 2003).

The LPGRP1 gene sequence exhibited sequence similarity with a number of wheat ESTs that have been physically mapped based on deletion bins spanning defined regions of the genetic map (Endo and Gill 1996; Qi et al. 2003). The highest matches were 
obtained with ESTs assigned to homoeologous groups 5AL, 5BL and 5DL (BE406557: $\left.\mathrm{E}=2 \times 10^{-26}\right), 3 \mathrm{BL}\left(\mathrm{BE} 485118: \mathrm{E}=1 \times 10^{-22}\right)$, and 2AS and 2BS $(\mathrm{BM} 140613: \mathrm{E}=4 \mathrm{x}$ $\left.10^{-16}\right)$, respectively. The highest-matching EST was also detected with high confidence by the wheat whGRP1 gene that was used to obtain the perennial ryegrass clone $(\mathrm{E}=2$ $\left.\mathrm{x} 10^{-30}\right)$.

\section{Discussion}

The cDNA sequences for glycine-rich RNA-binding proteins have been isolated from a number of plant species. The N-terminal RRM domain of such proteins are highly conserved, but the C-terminal glycine-rich region shows substantial diversity (see for example, Stephen et al. 2003). The LpGRP1 protein described here contained motifs typical of this protein family: the RNP-1 and RNP-2 sub-domain motifs, as well as glycine-rich sequence. The glycine-rich portion of this protein was relatively short (22 amino acids following Gly 86). The length of the glycine-rich sequence in the LpGRP1 protein is apparently one of the shortest reported, only a glycine-rich RNA-binding protein from a Medicago species is shorter (AF191305; Potenza et al. 2001). Sachetto-Martins et al. (2000) have suggested that diversity in the length of the glycine-rich region may be attributable to enhanced genetic recombination in regions of high GC content such as observed in the mammalian keratin family. In addition, the structure of the LPGRP1 gene glycine-rich region constitutes a simple sequence repeat (SSR) array with the structure $(\mathrm{GGC})_{5} \mathrm{~N}_{9}(\mathrm{GGC})_{5}$, and may consequently undergo expansions or contractions based on DNA polymerase-mediated replication slippage, as is typical of this sequence class (Weber and May 1989).

Through analysis of the LpGRP1 genomic DNA sequence, a single intron was identified within the coding region of the gene. The intron was located to a position between the RNP-2 and RNP-1 sub-domain motifs. Intron location was compared 
between reported genomic DNA sequences of plant glycine-rich RNA binding proteins, namely, maize (MA16, Gomez et al. 1988), Euphorbia esula (GRBP1 and GRBP2, Horvath and Olson 1998), Brassica napus (BnGRP10, for intron position, see Horvath and Olson 1998), Nicotiana sylvestris (RGP-3, Moriguchi et al. 1997), and Arabidopsis thaliana (Ccr1, for intron position, see Horvath and Olson 1998). The intron position between the RNP-2 and RNP-1 motifs is highly conserved between LpGRP1 and these genes (for the position of intron, see Fig. 1). This location is the sole intron type in both the LpGRP1 gene and all others apart from RGP-3, which contained in total 3 introns (within RNP-2, between RNP-2 and RNP-1, and downstream from RNP-1) (see Fig. 1; Moriguchi et al. 1997). This observation suggests that intron sequence was present between the sequences that encode the RNP-2 and RNP-1 sub-domains early in plant evolution, and that two more introns arose in other locations within the ancestral gene to RGP-3, subsequent to divergence from the other genes of this family.

In this study, changes in LpGRP1 mRNA level in response to environmental stresses were analyzed, revealing clear increases during cold treatment of plants. The increase started within $2 \mathrm{hr}$ after commencement of the cold treatment, continued for up to one week, and returned to pre-induction levels when plants were returned to normal temperature conditions. In general, the freezing tolerance of plants increases in proportion to the extent of increase in the period of cold acclimation. More than 7 days of cold treatment are required for achievement of the maximum level of freezing tolerance in perennial ryegrass (Lorenzetti et al. 1971). As a consequence, changes in LpGRP1 mRNA levels during cold treatment parallel the acquisition of freezing tolerance through cold acclimation, suggesting that the LpGRP1 protein may be closely associated with the transition to enhanced freezing tolerance. Electron microscopic analyses have revealed both enlargement of chloroplasts (potentially permitting increased accumulation of carbohydrates) and a proportionate decrease in the size of vacuoles (possibly permitting the removal of freezeable water from cells) during cold 
treatment of perennial ryegrass (Tominaga et al. 2004). The gradual changes in LpGRP1 mRNA level observed during cold treatment consequently occur in parallel to changes in the organellar structural properties, although these phenomena may be non-causally correlated rather than directly functionally associated. The results of Northern hybridisation analysis also demonstrated that induction of LpGRP1 expression occurs in response to $\mathrm{ABA}$ treatment and drought stress, in addition to cold treatment.

The cellular localization of the LpGRP1 protein was investigated by fusion with an EGFP reporter protein, revealing predominant localization in the nucleus. Studies of both gene expression in response to environmental stimuli and cellular protein localization suggest that the LpGRP1 protein has functions comparable to those of SaGRP-1a of S. alba (Heintzen et al. 1994) and/or RGP-3 of N. sylvestris (Moriguchi et al. 1997), which are also localized in the nucleus and have been inferred to be involved in pre-mRNA processing.

It is known that the mRNA levels of a large number of genes change during cold treatment in plants growing in temperate regions (see Pearce 1999). It is tempting to speculate that glycine-rich RNA binding proteins may function as RNA chaperones that stabilize various gene transcripts in cold environments. Due to their broad distribution and cold-inducible gene expression in a wide rage of organisms, glycine-rich RNA-binding protein may play fundamental roles in the adaptation of organisms to cold environments. In this context, a role for post-transcriptional control of a number of genes by glycine-rich RNA-binding proteins would not be unexpected.

The LpGRP1 gene was mapped as an RFLP locus (xlpgrp1) to the lower distal region of perennial ryegrass LG2. QTLs for winter hardiness in the field have been identified on LGs 2, 4, 6 and 7 in preliminary studies based on evaluation of the $\mathrm{F}_{2}$ (Aurora x Perma) population (Yamada and Forster 2005), which has been aligned with the p150/112 population-derived reference map (Armstead et al. 2002). The winter hardiness QTL on LG2 was closely linked to the extrapolated location of xlpgrp1. In the 
related species Festuca pratensis, major QTLs for frost tolerance/winter survival have been mapped on LGs 1, 2, 5, and 6 (Alm et al. 2005). Co-location of stress-related genes with QTLs for stress tolerance has been previously reported in other members of the Poaceae family, especially the Triticeae cereals (reviewed by Cattivelli et al. 2002). The cold-regulated transcriptional activator, C-repeat binding factor (CBF) 3, was linked to the frost-tolerance locus Fr-A2 on wheat chromosome 5A (Vagujfalvi et al. 2003). The genes of the CBF family were also co-incident with a QTL for cold tolerance in barley (Francia et al. 2004). However, the long arms of the homoeologous group 2 chromosomes of the Triticeae (2A, 2B and 2D of wheat, as well as $2 \mathrm{H}$ of barley) have not to date been identified as major sites for QTLs associated with cold tolerance. Recently, analysis of genomic introgression between winter susceptible Lolium multiflorum and the winter tolerant species Festuca pratensis revealed that a derived freezing-tolerant genotype contained a Festuca introgression segment in a terminal region of Lolium chromosome 2 (Kosmala et al. 2005). As LG2 of perennial ryegrass is the syntentic counterpart of the Triticeae group 2 chromosomes, the observation of QTL-candidate gene co-location on LG2, as well as associated functional data reported in this study, may indicate that some of the genes commonly showing allelic variation for winter hardiness differ between the pasture grasses and the cereals. However, it is very likely, on the basis of comparative genetics and genomics studies, that the basic repertoire of genes involved in cold tolerance mechanisms is highly conserved between the two groups.

\section{Acknowledgements}

We thank Dr. J. Abe for valuable discussion and Dr. R. Imai for technical advices and information about wheat glycine-rich RNA-binding protein gene. We also thank Dr. K. Fujino for providing a plasmid DNA. This work was supported in part by Grants-in-Aid for Scientific Research from the Ministry of Education, Culture, Sports, Science and 
Technology of Japan.

\section{References}

Alba MM, Pages M (1998) Plant proteins containing the RNA-recognition motif. Trends Plant Sci 3:15-21

Alba M, Culianez-Macia FA, Goday A, Freire MA, Nadal B, Pages M (1994) The maize RNA-binding protein, MA16, is a nucleolar protein located in the dense fibrillar component. Plant J 6:825-834

Alm V, Fang C, Busso CS, Devos KM, Vollan K, Grieg Z, Rognli OA (2003) A linkage map of meadow fescue (Festuca pratensis Huds.) and comparative mapping with other Poaceae species. Theor Appl Genet 108:25-40

Alm V, Busso CS, LarsenA, Humphreys MW, Rognli OA (2005) Quantitative trait loci for frost tolerance, winter survival and drought tolerance in meadow fescue (Festuca pratensis Huds.), and comparative mapping with cereals. Genetics (in press)

Armstead IP, Turner LB, King IP, Cairns AJ, Humphreys MO (2002) Comparison and integration of genetic maps generated from $\mathrm{F}_{2}$ and $\mathrm{BC}_{1}$-type mapping populations in perennial ryegrass. Plant Breed 121:501-507

Cattivelli L, Baldi P, Crosatti C, Di Fonzo N, Faccioli P, Grossi M, Mastrangelo AM, Pecchioni N, Stanca AM (2002) Chromosome regions and stress-related sequences involved in resistance to abiotic stress in Triticeae. Plant Mol Biol 48:649-665

Cronn R, Cedroni M, Haselkorn T, Grover C, Wendel JF (2002) PCR-mediated recombination in amplified products derived from polyploid cotton. Theor Appl Genet 104:482-489

Derry JMJ, Kerns JA, Francke U (1995) RBM3, a novel human gene in Xp11.23 with a putative RNA-binding domain. Hum Mol Genet 4:2307-2311

Doyle JJ, Doyle JL (1987) A rapid DNA isolation procedure for small quantities of fresh leaf tissue. Phytochem Bull 19:11-15 
Dubouzet JG, Sakuma Y, Ito Y, Kasuga M, Dubouzet EG, Miura S, Seki M, Shinozaki K, Yamaguchi-Shinozaki K (2003) OsDREB genes in rice, Oryza sativa L., encode transcription activators that function in drought-, high-salt- and cold-responsive gene expression. Plant J 33:751-763

Dunn MA, Brown K, Lightowlers R, Hughes MA (1996) A low-temperature-responsive gene from barley encodes a protein with single-stranded nucleic acid-binding activity which is phosphorylated in vitro. Plant Mol Biol 30:947-959

Dunn MA, White AJ, Vural S, Hughes MA (1998) Identification of promoter elements in a low-temperature-responsive gene (blt4.9) from barley (Hordeum vulgare L.). Plant Mol Biol 38:551-564

Endo TR, Gill BS (1996) The deletion stocks of common wheat. J Hered 87:95-307

Francia E, Rizza F, Cattivelli L, Stanca AM, Galiba G., Toth B, Hayes PM, Skinner JS, Pecchioni N (2003) Two loci on chromosome 5H determine low-temperature tolerance in a 'Nure' (winter) x 'Tremois' (spring) barley map. Theor Appl Genet 108:670-680

Gendra E, Moreno A, Alba MM, Pages M (2004) Interaction of the plant glycine-rich RNA-binding protein MA16 with a novel nucleolar DEAD box RNA helicase protein from Zea mays. Plant J 38:875-886

Gomez J, Sanchez-Martinez D, Stiefel V, Rigau J, Puigdomenech P, Pages M (1988) A gene induced by the plant hormone abscisic acid in response to water stress encodes a glycine-rich protein. Nature 334:262-264

Guiltinan MJ, Niu X (1996) cDNA encoding a wheat (Triticum aestivum cv. Chinese Spring) glycine-rich RNA-binding protein. Plant Mol Biol 30:1301-1306

Hall TA (1999) BioEdit: a user-friendly biological sequence alignment editor and analysis program for Windows 95/98/NT. Nucleic Acids Symp Ser 41:95-98

Hanano S, Sugita M, Sugiura M (1996) Isolation of a novel RNA-binding protein and its association with a large ribonucleoprotein particle present in the nucleoplasm of 
tobacco cells. Plant Mol Biol 31:57-68

Harmer SL, Hogenesch JB, Straume M, Chang HS, Han B, Zhu T, Wang X, Kreps JA, Kay SA (2000) Orchestrated transcription of key pathways in Arabidopsis by the circadian clock. Science 290:2110-2113

Heintzen C, Melzer S, Fischer R, Kappeler S, Apel K, Staiger D (1994) A light- and temperature-entrained circadian clock controls expression of transcripts encoding nuclear proteins with homology to RNA-binding proteins in meristematic tissue. Plant J 5:799-813

Higo K, Ugawa Y, Iwamoto M, Korenaga T (1999) Plant cis-acting regulatory DNA elements (PLACE) database:1999. Nucleic Acids Res 27:297-300

Hirose T, Sugita M, Sugiura M (1993) cDNA structure, expression and nucleic acid-binding properties of three RNA-binding proteins in tobacco: occurrence of tissue-specific alternative splicing. Nucleic Acids Res 21:3981-3987

Hisano H, Kanazawa A, Kawakami A, Yoshida M, Shimamoto Y, Yamada T (2004) Transgenic perennial ryegrass plants expressing wheat fructosyltransferase genes accumulate increased amounts of fructan and acquire increased tolerance on a cellular level to freezing. Plant Sci 167:861-868

Horvath DP, Olson PA (1998) Cloning and characterization of cold-regulated glycine-rich RNA binding protein genes from leafy spurge (Euphorbia esula L.) and comparison to heterologous genomic clones. Plant Mol Biol 38:531-538

Humphreys MW, Humphreys J, Donnison I, King IP, Thomas HM, Ghesquiere M, Durand J-L, Rognli OA, Zwierzykowski Z, Rapacz M (2004) Molecular breeding and functional genomics for tolerance to abiotic stress. In: Molecular breeding of forage and turf, Hopkins A, Wang ZY, Mian R, Sledge M, Barker RE (eds.), pp. 61-80. Kluwer Academic Publishers, Netherland

Jones ES, Mahoney NL, Hayward MD, Armstead IP, Jones JG, Humphreys MO, King IP, Kishida T, Yamada T, Balfourier F, Charmet G, Forster JW (2002a) An enhanced 
molecular marker based genetic map of perennial ryegrass (Lolium perenne) reveals comparative relationships with other Poaceae genomes. Genome 45:282-295

Jones ES, Dupal MP, Dumsday JL, Hughes LJ, Forster JW (2002b) An SSR-based genetic linkage map for perennial ryegrass (Lolium perenne L.). Theor Appl Genet $105: 577-584$

Kosambi DD (1944) The estimation of map distances from recombination values. Ann Eugen 12:172-175

Kosmala A, Zwierzykowski Z, Gąsior D, Rapacz M, Zwierzykowska E, Humphreys MW (2005) GISH/FISH mapping of genes for freezing tolerance transferred from Festuca pratensis into Lolium multiflorum. Heredity (in press)

Lander ES, Green P, Abrahamson J, Barlow A, Daly MJ, Lincoln SE, Newburg L (1987) MAPMAKER: an interactive computer package for constructing primary linkage maps of experimental and natural populations. Genomics 1:174-181

Lorenzetti F, Tyler BF, Cooper JP, Breese EL (1971) Cold tolerance and winter hardiness in Lolium perenne. 1. Development of screening techniques for cold tolerance and survey of geographical variation. J Agric Sci 76:199-209

Ludevid MD, Angel Freire M, Gomez J, Burd CG, Albericio F, Giralt E, Dreyfuss G, Pages M (1992) RNA binding characteristics of a $16 \mathrm{kDa}$ glycine-rich protein from maize. Plant J 2:999-1003

Marcotte Jr WR, Russel SH, Quatrano RS (1989) Abscisic acid-responsive sequences from the Em gene of wheat. Plant Cell 1:969-9776

Maruyama K, Sato N, Ohta N (1999) Conservation of structure and cold-regulation of RNA-binding proteins in cyanobacteria: probable convergent evolution with eukaryotic glycine-rich RNA-binding proteins. Nucleic Acids Res 27:2029-2036

Moriguchi K, Sugita M, Sugiura M (1997) Structure and subcellular localization of a small RNA-binding protein from tobacco. Plant J 12:215-221

Murashige T, Skoog F (1962) A revised medium for rapid growth and bioassays with 
tobacco tissue cultures. Physiol Plant 15:473-497

Napoli C, Lemieux C, Jorgensen R (1990) Introduction of a chimeric chalcone synthase gene into petunia results in reversible co-suppression of homologous genes in trans. Plant Cell 2:279-289

Nishiyama H, Itoh K, Kaneko Y, Kishishita M, Yoshida O, Fujita J (1997) A glycine-rich RNA-binding protein mediating cold-inducible suppression of mammalian cell growth. J Cell Biol 137:899-908

Pearce RS (1999) Molecular analysis of acclimation to cold. Plant Growth Regulation 29:47-76

Potenza C, Thomas SH, Sengupta-Gopalan C (2001) Genes induced during early response to Meloidogyne incongnita in roots of resistant and susceptible alfalfa cultivars. Plant Sci 161:289-299

Qi L, Echalier B, Friebe B, Gill BS (2003) Molecular characterisation of a set of wheat deletion stocks for use in chromosome bin mapping of ESTs. Funct. Integr. Genomics $3: 39-55$

Sachetto-Martins G, Franco LO, de Oliveira DE (2000) Plant glycine-rich proteins: a family or just proteins with a common motif? Biochim Biophys Acta 1492:1-14

Sano Y, Tanaka I (2005) A histone H3.3-like gene specifically expressed in the vegetative cell of developing lily pollen. Plant Cell Physiol 46:1299-1308

Sato N (1994) A cold-regulated cyanobacterial gene cluster encodes RNA-binding protein and ribosomal protein S21. Plant Mol Biol 24:819-823

Sidebottom C, Buckley S, Pudney P, Twigg S, Jarman C, Holt C, Telford J, McArthur A, Worrall D, Hubbard R, Lillford P (2000) Heat-stable antifreeze protein from grass. Nature 406:256

Staiger D, Zecca L, Kirk DAW, Apel K, Eckstein L (2003) The circadian clock regulated RNA-binding protein AtGRP7 autoregulates its expression by influencing alternative splicing of its own pre-mRNA. Plant J 33:361-371 
Stephen JR, Dent KC, Finch-Savage WE (2003) A cDNA encoding a cold-induced glycine-rich RNA binding protein from Prunus avium expressed in embryonic axes. Gene 320:177-183

Sugita M, Sugiura M (1994) The existence of eukaryotic ribonucleoprotein consensus sequence-type RNA-binding proteins in a prokaryote, Synechococcus 6301. Nucleic Acids Res 22:25-31

Thompson JD, Higgins DG, Gibson TJ (1994) CLUSTAL W: improving the sensitivity of progressive multiple sequence alignment through sequence weighting, positions-specific gap penalties and weight matrix choice. Nucleic Acids Res $22: 4673-4680$

Tominaga Y, Kanazawa A, Shimamoto Y (2001) Identification of cold-responsive genes in perennial ryegrass (Lolium perenne L.) by a modified differential display method. Grassland Sci 47:516-519

Tominaga Y, Kanazawa A, Shimamoto Y (2004) Changes in the structural properties of chloroplasts and mitochondria in response to low temperature in perennial ryegrass (Lolium perenne L.). Grassland Sci 50:31-39

Vagujfalvi G, Galiba G, Cattivelli L, Dubcovsky J (2003) The cold-regulated transcriptional activator $C b f 3$ is linked to the frost-tolerance locus $F r-A 2$ on wheat chromosome 5A. Mol Genet Genomics 269:60-67

van Nocker S, Vierstra RD (1993) Two cDNAs from Arabidopsis thaliana encode putative RNA binding proteins containing glycine-rich domains. Plant Mol Biol 21:695-699

Wang YJ, Li YD, Luo GZ, Tian AG, Wang HW, Zhang JS, Chen SY (2005) Cloning and characterization of an HDZip I gene GmHZ1 from soybean. Planta 221:831-843

Weber JJ, May PE (1989) Abundant class of human DNA polymorphism which can be typed using the polymerase chain reaction. Am J Hum Genet 44:388-396

Yamada T, Forster JW (2005) QTL analysis and trait dissection in ryegrass (Lolium 
spp.). In: Molecular Breeding for the Genetic Improvement of Forage and Turf, Humphreys MO ed., Wageningen Academic Publishers, pp 43-53

Yamada T, Jones ES, Cogan NOI, Vecchies AC, Nomura T, Hisano H, Shimamoto Y, Smith KF, Hayward MD, Forster JW (2004) QTL analysis of morphological, developmental, and winter hardiness-associated traits in perennial ryegrass. Crop Sci 44:925-935

Yamashita M, Abe J, Shimamoto Y (1993) Relation between cold hardiness and Aco-1 in perennial ryegrass (Lolium perenne L.). Res Bull Univ Farm, Hokkaido Univ $28: 25-30$ 


\section{Legends of figures}

Fig. 1 Multiple alignment of plant glycine-rich RNA-binding protein sequences. The RNP-1 and RNP-2 motifs are indicated above the sequence. The conserved amino acids are shown in shading. Amino acids common to all the aligned sequences are shown by asterisks below the sequence. The aligned sequences are A. thaliana AtGRP7 (Z14987; van Nocker and Vierstra, 1993), S. alba SaGRP1a (L31374; Heintzen et al., 1994), L. perenne LpGRP1 (AB207971; this study), Hordeum vulgare Blt801 (U49482; Dunn et al., 1996), N. sylvestris NsRGP1b (D16205; Hirose et al., 1993), Zea mays MA16 (X12564; Gomez et al. 1988), and N. sylvestris NsRGP3 (D67086; Moriguchi et al. 1997). The filled triangle and open triangles indicate positions of intron in LpGRP1 and NsRGP3, respectively. Numbers on the right refer to amino acid position from the N-terminal methionine.

Fig. 2 Nucleotide and predicted amino acid sequences of the LpGRP1 gene. The RNP-2 and RNP-1 motifs are boxed. Nucleotide sequences present in the cDNA are shown by uppercase letters. The predicted amino acid sequence is shown under the nucleotide sequence. Numbers on the right refer to the nucleotide position of this region as well as amino acid position from the N-terminal methionine. The putative TATA box and regulatory elements as well as restriction sites are indicated below the sequence.

Fig. 3 Changes in the mRNA levels of the $L p G R P 1$ gene in the crown tissues of plants depending on the environmental conditions. (A) Northern hybridisation analysis of RNA extracted from crown tissues of plants treated at $4^{\circ} \mathrm{C}$ for 1 day, 3 days, 7 days, and 14 days, treated at normal temperature $\left(22^{\circ} \mathrm{C}\right)$ after 14 days of the $4^{\circ} \mathrm{C}$ treatment (deacclimation), and of control plants (0 day). (B) Northern hybridisation analysis of RNA extracted from crown tissues of plants treated at $4^{\circ} \mathrm{C}$ for $2 \mathrm{hr}$ and $6 \mathrm{hr}$, treated with 
$0.1 \mathrm{mM} \mathrm{ABA}$ for $4 \mathrm{hr}$, and treated with drought for $2 \mathrm{hr}$, and of control plants. (C) Northern hybridisation analysis of RNA extracted from roots, crown and leaf tissues of plants treated at $4^{\circ} \mathrm{C}$ for $6 \mathrm{hr}(6 \mathrm{~h} \mathrm{LT})$, and of control plants. RNA (10 $\left.\mu \mathrm{g}\right)$ was separated on a $1 \%(\mathrm{w} / \mathrm{v})$ agarose gel, transferred to membrane and hybridised with labelled LpGRP1 cDNA. The EtBr-stained rRNA bands indicate that equal amount of RNA was loaded in each lane. Corresponding positions of rRNA bands on the hybridised membranes are shown on the left side of the panels A and B.

Fig. 4 Subcellular localization of the LpGRP1 protein, shown by representative images of nuclei from transiently transformed onion epidermal cells expressing an EGFP fusion to the LpGRP1 protein. Images of DAPI staining (A), EGFP fluorescence (B), and lighting (C), and EGFP fluorescence signal overlaid with lighting image (D) are shown. The EGFP gene alone was introduced into cells as a control (E). Bar $=50 \mu \mathrm{m}$. 


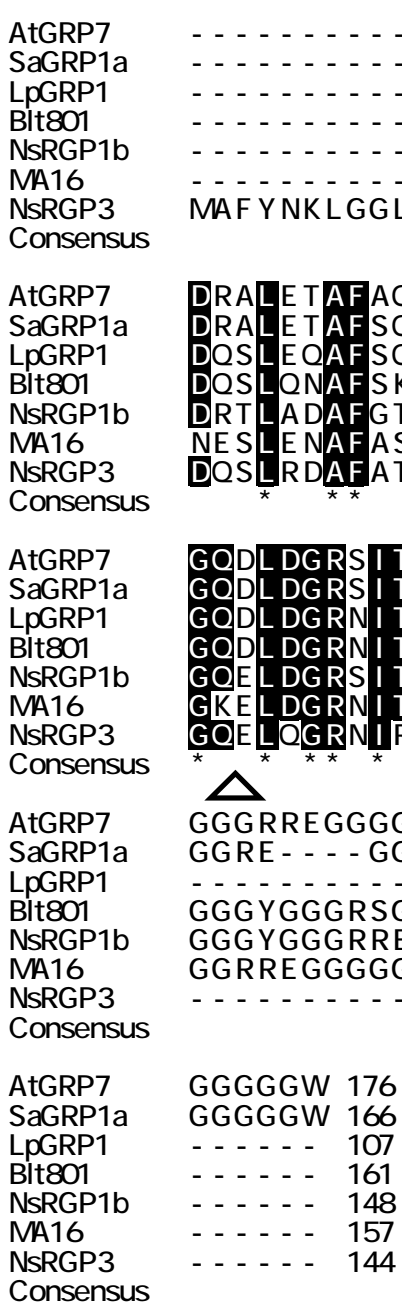


ccgcct gacc cgat cagcaa gt gggggttg gt gggagcgc gagaaacgag aacgcaaacc 60

ct at acgct c cct cccoggc cgaaat at c tcgt ggcgga gagt cagt ga gggtccaat c 120 LTRE circadian

gt gggctggc tggcccagaa acttagaaaa ctcctcgagc ccatcaagga cggcagaaaa 180

circadian

tatctcctcc ctcccagaaa accettat ct caaggcaagg caaccgt cgg at ccgat cac 240

gacgtcccce cgt ggcgccg cgcggcctat aaaat cgggg gcaggccgac ct gt ctcct 300

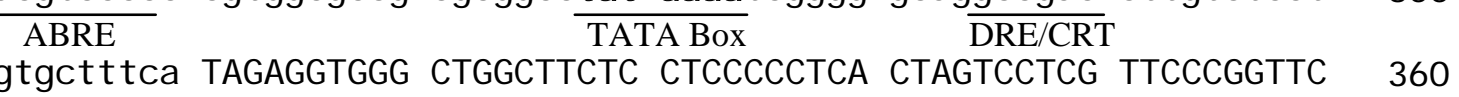

cgt gct tt Ca TAGAGGTGG CTGGCTTCTC CTCCCCCTCA CTAGTCCTCG TTCCCGGITC 360
RNP2 -

CGGTTCGTCT AGTAGGGTाT AGCGGCAAGA $\underset{M}{\mathrm{M}}$ GCG GAA GAG TAC CGT TTGC TTC 414

GTC GGC GGC CTC GCC TGG GCC ACC AAC GAC CAG TCC CTC GAG CAG GCC 462

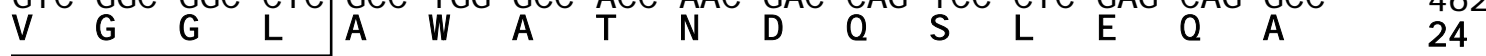

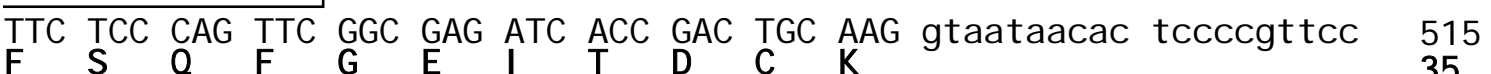

catccgat ag atctcatgtg ttttctgaga cagatctgag at agatctgc tcgettctcc 575

gacctcaaag aaacgtagat ctgagttcta ggat ctgact atgtttgct tgcgcag 632

ATC ATC AAC GAC AGG GAG ACG GGC CGT TCC $\overline{\text { CGC GGC TTC GGC TTC GTC }} 680$

\begin{tabular}{lllllllllllllllll}
$I$ & $I$ & $N$ & $D$ & $R$ & $E$ & $T$ & $G$ & $R$ & $S$ & $R$ & $G$ & $F$ & $G$ & $F$ & $V$ & \\
\hline
\end{tabular}

ACC TTC TCG AGC TCC GAG TCG ATG AAG AAC GCC ATC GAG GGG ATG AAC 728

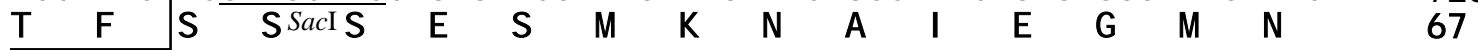

GGC CAG GAC CTG GAC GGC CGC AAC ATC ACC GTC AAC GAG GCG CAG TCC 776

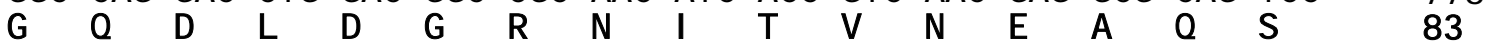

CGC TCC GGC GGC GGC GGC GGC GGC TAC TCC CGC GGC GGC GGC GGC GGT 824

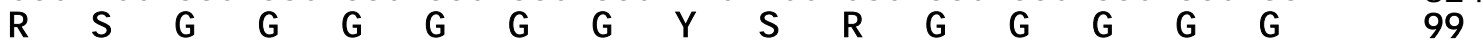

GAC TCT GCC GGC AAC TGG AGG AAC TGA TTGGTGG GGCCACGAGT GGCCAGTTAT 877

$\begin{array}{llllllllll}D & S & A & G & N & W & R & N & * & 107\end{array}$

CCTAGCTATC CTACCCCTIT GTGITCTIT GTTATCGCCC CGTCCCCAGA GAGTATCCTA 937

GGTCTCGCTC CATCGCTTAG GGITTGAGAC GATTATGGCT ACCATTAGGT GTCTGTGTTA 997

CCATCGTGTT CCCTTGTTAC TATTCTGTTC GCTATCATCG CCGAGAAACT GAAATGAGAA 1057

AATGAGTGGG CCTGGTTCTG TTCGCat ct c cgttcgt cet cgtctgettg ct that acg 1117 
Fig. 3

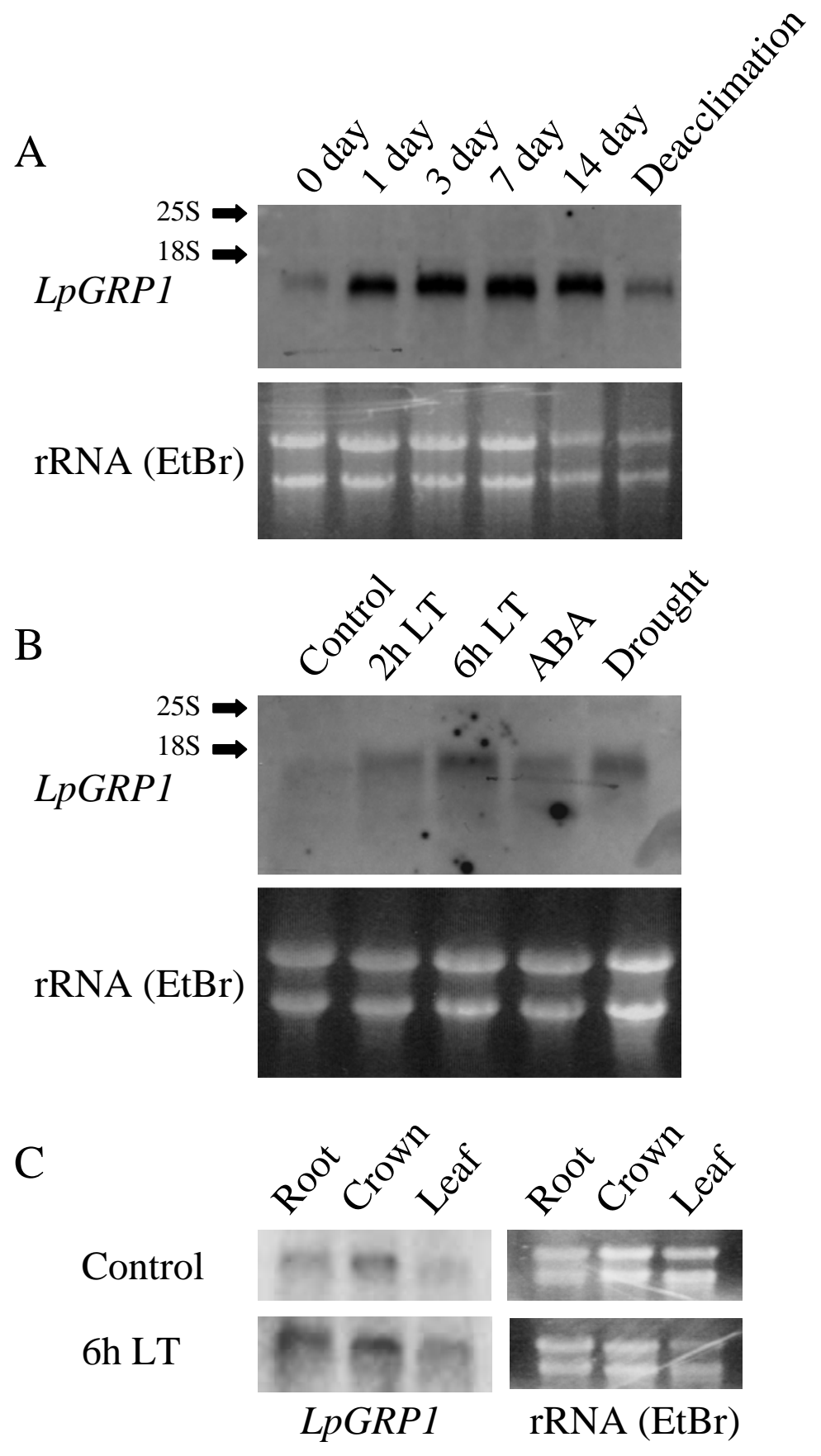


Fig. 4
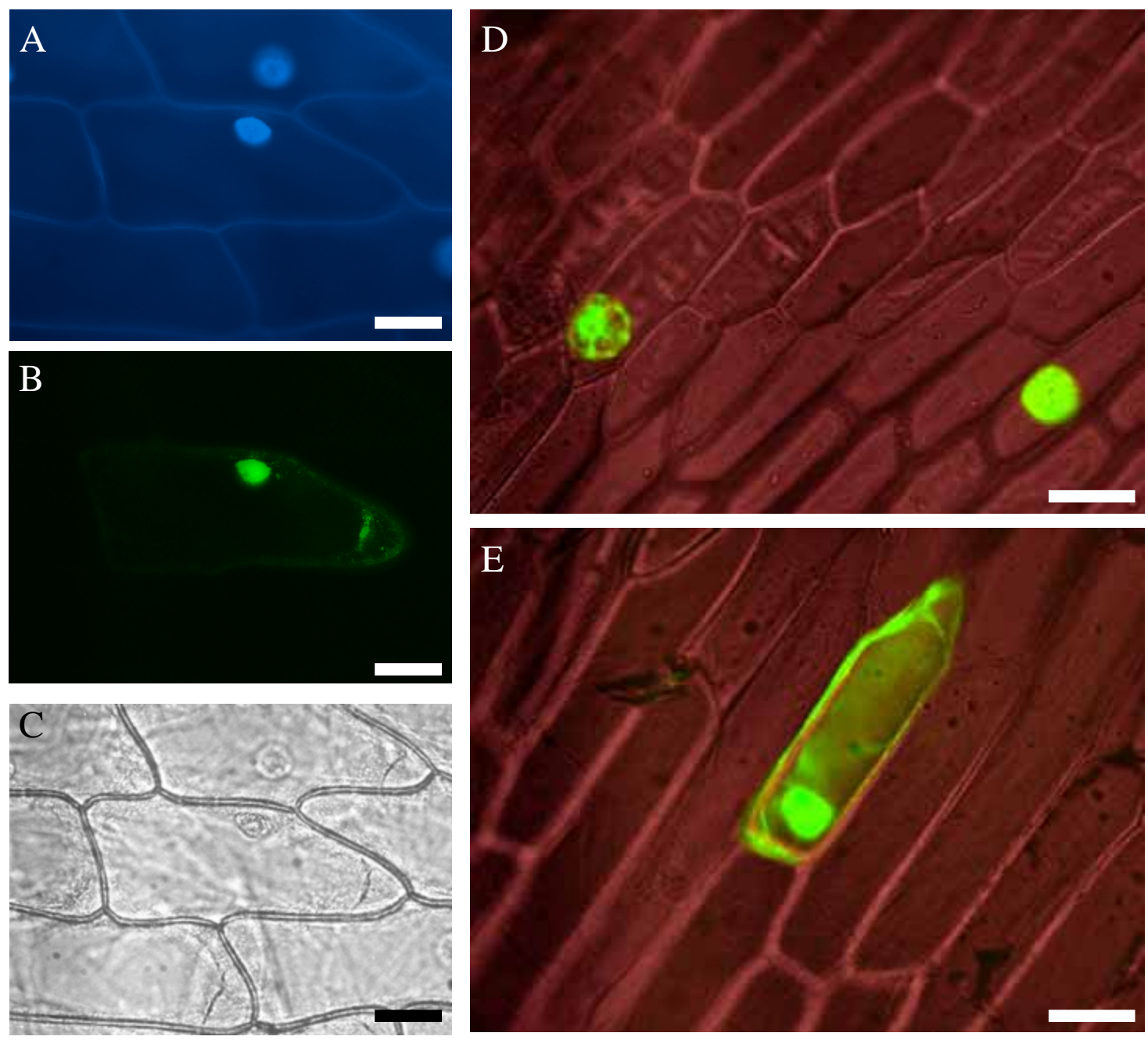